Article

\title{
Application of Social Vulnerability Indicators to Climate Change for the Southwest Coastal Areas of Taiwan
}

\author{
Chin-Cheng Wu ${ }^{1}$, Hao-Tang Jhan ${ }^{2}$, Kuo-Huan Ting ${ }^{3}$, Heng-Chieh Tsai ${ }^{1}$, Meng-Tsung Lee ${ }^{4}$, \\ Tai-Wen $\mathrm{Hsu}^{5, *}$ and Wen-Hong $\mathrm{Liu}^{3, *}$ \\ 1 Department of Fisheries Production and Management, National Kaohsiung Marine University, \\ Kaohsiung 81157, Taiwan; ccwu@mail.nkmu.edu.tw (C.-C.W.); alanztsai@gmail.com (H.-C.T.) \\ 2 School of Earth \& Ocean Sciences, Cardiff University, Cardiff CF10 3AT, UK; JhanHT@cardiff.ac.uk \\ 3 Center for Marine Affairs Studies, Institute of Marine Affairs and Business Management, \\ National Kaohsiung Marine University, Kaohsiung 81157, Taiwan; dgh0809@gmail.com \\ 4 Department of Marine Leisure Management, National Kaohsiung Marine University, \\ Kaohsiung 81157, Taiwan; lmasonlee@webmail.nkmu.edu.tw \\ 5 Department of Harbor \& River Engineering, National Taiwan Ocean University, Keelung 202, Taiwan \\ * Correspondence: twhsu@mail.ntou.edu.tw (T.-W.H.); andersonliu@mail.nkmu.edu.tw (W.-H.L.); \\ Tel.: +886-2-2462-2192 (ext. 6104) (T.-W.H.); +886-7-361-7141 (ext. 3528) (W.-H.L.)
}

Academic Editor: Yosef Jabareen

Received: 11 August 2016; Accepted: 29 November 2016; Published: 7 December 2016

\begin{abstract}
The impact of climate change on the coastal zones of Taiwan not only affects the marine environment, ecology, and human communities whose economies rely heavily on marine activities, but also the sustainable development of national economics. The southwest coast is known as the area most vulnerable to climate change; therefore, this study aims to develop indicators to assess social vulnerability in this area of Taiwan using the three dimensions of susceptibility, resistance, and resilience. The modified Delphi method was used to develop nine criteria and 26 indexes in the evaluation, and the analytic hierarchy process method was employed to evaluate the weight of each indicator based on the perspectives of experts collected through questionnaire surveys. The results provide important information pertaining to the vulnerability of the most susceptive regions, the lowest-resistance areas, and the least resilient townships on the southwest coast. The most socially vulnerable areas are plotted based on the present analysis. Experts can consider the vulnerability map provided here when developing adaptation policies. It should be kept in mind that improving the capacities of resistance and resilience is more important than reducing susceptibility in Taiwan.
\end{abstract}

Keywords: sustainable development; climate change; social vulnerability index; Delphi method; analytic hierarchy process

\section{Introduction}

Over the past few years, climate change has become the most challenging global issue of this century [1]. The risk brought about by climate change and its imperativeness is recognized on an international level [2]. About two-thirds of major cities worldwide-in which $40 \%$ of the world's population lives - are situated within 60 miles of a coastline. Note that climate change directly or potentially impacts coastal populations in terms of their ecosystems and natural environments $[3,4]$. Extreme weather, ocean climate conditions, and coastal disasters resulted in severe losses in and damage to the coastal areas worldwide [5,6]. Moreover, approximately 100 million people live in areas located less than $1 \mathrm{~m}$ above sea level [7,8]. In Asia, particularly, many people are threatened by flooding, where about 60,000 lives were taken and two million people were impacted by floods during 
the period of 1994 to 2004 [9]. Climate change and the associated risks have become a major concern for human beings; thus, how to mitigate and live alongside these changes must be understood [2].

In the context of this research, vulnerability is a consequence of various potential elements for loss $[10,11]$. A clear definition of the key components of vulnerability is necessary to further the theoretical and practical realization of how and why places and people are vulnerable. The first aspect, namely susceptibility, is defined $[12,13]$ as the "degree to which a system is open, liable, or sensitive to climate stimuli". The second (resistance) and third aspects (resilience) relate to the societal response to and capability to recover from hazards. Timmerman (1981) defines vulnerability as "the measure of a system or part of a system's capacity to absorb and recover from the occurrence of a hazardous event" [14]. This emphasizes that vulnerability is linked to individuals and social resilience and resistance to hazards $[15,16]$. Knowledge of the vulnerability of coastal zones to climate change can help scientists and policy-makers identify and prioritize management ability to decrease risks and mitigate possible impacts [17]. Mitigation of coastal disasters must consider both extreme conditions and social impacts [18]. Social vulnerability is the most significant index after coastal disasters occur, as it evaluates the experiences and recovery situations of specific groups [19] such as women, children, the elderly, and the poor, who are most likely to be affected. White [20] found that political, economic, and social conditions influence the engineering effectiveness of disaster prevention. Therefore, White and Haas [21] investigated related issues in the cross-disciplines of economy, society, and politics. These indicators have been widely used to measure social vulnerability since the 1990s, and previous studies [19,22-27] categorized these indicators into the three distinctive aspects of vulnerability assessment, namely susceptibility, resistance, and resilience.

The average annual precipitation of Taiwan is 2.6 times that of the world. However, due to highly uneven temporal and spatial distribution as well as geographical characteristics such as the steepness of riverbanks and lack of backlands, only $20 \%$ of the runoff volume can be utilized, with the rest causing floods and other damage [28]. Though the accumulated precipitation does not fluctuate greatly, enlarged variation between the wet and dry seasons causes greater seasonal differences and an increased chance of heavy rains. Taiwan ranks 16th in the Coastal Vulnerability Index (CVI) of United Nations Environment Programme (UNEP) [29], and is probably among the first to be negatively affected by the rising sea level. Floods are the most obvious and common disaster resulting from climate change in the coastal areas of Taiwan. Currently, the country has areas totaling about $1150 \mathrm{~km}^{2}$ which can potentially flood [30]. Most are located on the western coast in areas such as ChangHua, Yulin, Chiayi, Tainan, Kaohsiung, and Pingtung. These coastal areas are characterized by low-lying terrain, and the confluence of rivers [30].

It is important to note that the country's population is concentrated in coastal areas, which account for about $25 \%$ of the total area of the island. The subsequent intense use of these areas increases the probability of environmental disasters, increasing susceptibility and decreasing the resilience of coastal communities. Residents from the southwest coastal areas are known as the first group of climate refugees. They experience frequent floods mostly due to persisting land subsidence, storm wave destruction, the rising sea level, an increase in heavy rain, rampageous inundation, and saltwater intrusion. Therefore, the southwest coastal area is the area most vulnerable to climate change in Taiwan.

The primary goal of this study is to develop social vulnerability indicators using the three dimensions of susceptibility, resistance, and resilience to assess social vulnerability due to climate change in the southwest coastal area of Taiwan. This study first analyzes the present situation of the southwest coast of Taiwan and the influences of climate change. Historical data of losses caused by coastal disasters were used to establish the database for assessing socioeconomic vulnerability. We also reviewed socioeconomic vulnerability indicators used domestically and abroad. This analysis enabled us to establish indicator groups to evaluate susceptibility, resistance, resilience, and social vulnerability. Upon applying the modified Delphi method to indicator selection and the analytic hierarchy process method in data synthesis, the socioeconomic vulnerability of the southwestern coast was determined and the vulnerability map plotted accordingly. Finally, the paper discusses key findings and implications of the social vulnerability analysis. 


\section{Climate Change in Taiwan}

The present study focuses on the cities located on the southwest coast, which are within zones regulated by integrated sustainable coastal zone development plans. Figure 1 shows the counties in the coastal area, namely Chiayi, Tainan, Kaohsiung, and Pingtung. Demographic data provided by Hsu et al. [28] indicates that the population has decreased over the past 10 years. Tainan City districts have the highest population densities in Taiwan, and within these districts, the most densely populated is Anping District, with 5477 people per km.

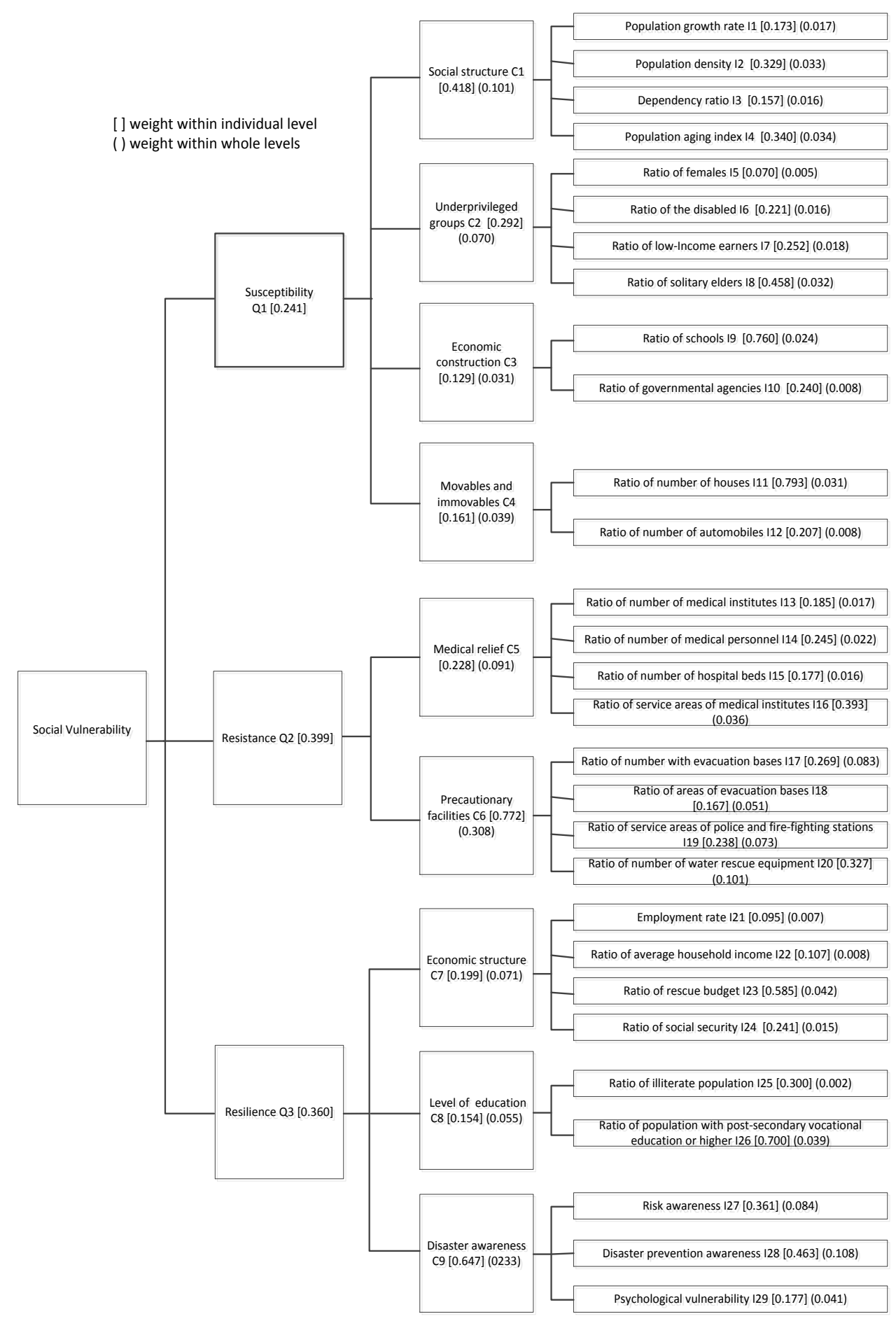

Figure 1. Social vulnerability indicator framework for climate change in the southwestern coastal areas of Taiwan. 
Based on statistical records of agricultural and fishery losses in 2009, Typhoon Morakot caused NT\$800 million (NT\$1 = \$0.031) in losses in the Qigu District of Tainan. In Pingtung, losses totaled NT\$16,154,096 for farming in an area of 486 acres, NT\$169,620,000 for fishery, and NT\$1,725,000 for livestock farming. Flooding was also a threat. A total of $14,081,107.8 \mathrm{~km}$ was flooded in Xinyuan, Pingtung, with a maximum depth of approximately $110 \mathrm{~cm}$, affecting 10,222 households [31].

\subsection{Typhoon Surge Inundation}

Hsu et al. (2011) estimated the tendency of the sea level to rise due to climate change for 2020 and 2039. Their results concluded that the rise in sea level is in the range of $10.19 \mathrm{~cm}$ to $14.57 \mathrm{~cm}$ for Chiayi and Tainan, and $8.20 \mathrm{~cm}$ to $14.35 \mathrm{~cm}$ for Kaohsiung, respectively. This result is similar to the estimated value of $59 \mathrm{~cm}$ for the 21st century according to the Fourth Assessment Report of the Intergovernmental Panel on Climate Change (IPCC) [28]. For changes to the waves and storm surges caused by typhoons, Hsu et al. (2011) applied wind wave modeling (WWM) and the typhoon surge model to simulate the maximum wave height and maximum tide level near the Zengwun River and Kaoping River outlet for recent years (1980-1999) and target years (2020-2039). The results revealed that the maximum wave height and maximum tide level would increase $45 \%$ and $39 \%$ for Chiayi and Tainan and 50\% and 27\% for Kaohsiung and Pingtung.

\subsection{Flood Simulation}

A coastal flooding simulation for the southwest coast was conducted by Hsu et al. (2011) using the integrated WASH123D model of the 1D Stream-River Network, 2D Overland Regime, and 3D Subsurface Media [28]. The boundary conditions of the simulation included flooding in coastal areas, upstream rainfall, downstream typhoon surges, and wave topping. The results indicate that the Kaohsiung Township, Cheting District, Agongdian River, Zuoying District, Kaohsiung River, and Xiaogang District are prone to floods because of low-lying terrain where the surface elevation of most aquiculture and agriculture land areas is less than $2 \mathrm{~m}$. In Pingtung, areas downstream of the Donggang River, Linbian River, and Fangliao coast also have a higher potential for flooding given the imperfect drainage system of sea walls or land subsidence.

\section{Methodology}

Previous studies $[12,13,15,16]$ suggest that social vulnerability relates to society's resistance, resilience, and the potential susceptibility of local areas to hazard. Therefore, the dimensions of social vulnerability in this study include susceptibility, resistance, and resilience.

The study builds a candidate indicator group (Table 1) grounded in numerous local and international empirical studies $[19,32,33]$ and provides the background to the southwestern coastal areas of Taiwan. Finally, the modified Delphi method and analytic hierarchy process method are employed in the selection of indicators, the allocation of the weight of each indicator, and the aggregation of indicators, respectively. 
Table 1. Social vulnerability index for climate change.

\begin{tabular}{|c|c|c|c|c|c|c|c|c|c|c|c|c|c|c|}
\hline Municipality & Township/District & $\begin{array}{c}\text { Social } \\
\text { Vulnerability }\end{array}$ & Susceptibility & Resistance & Resilience & $\begin{array}{c}\text { Social } \\
\text { Structure } \\
\end{array}$ & $\begin{array}{l}\text { Underprivileged } \\
\text { Groups }\end{array}$ & $\begin{array}{c}\text { Economic } \\
\text { Construction }\end{array}$ & $\begin{array}{c}\text { Movables and } \\
\text { Immovables }\end{array}$ & $\begin{array}{c}\text { Medical } \\
\text { Relief }\end{array}$ & $\begin{array}{l}\text { Precautionary } \\
\text { Facilities }\end{array}$ & $\begin{array}{l}\text { Economic } \\
\text { Structure }\end{array}$ & $\begin{array}{l}\text { Educational } \\
\text { Levels }\end{array}$ & $\begin{array}{c}\text { Disaster } \\
\text { Awareness }\end{array}$ \\
\hline Chiayi & Dongshi & 0.641 & 0.610 & 0.283 & 0.421 & 0.644 & 0.843 & 0.400 & 0.266 & 0.306 & 0.276 & 0.397 & 0.108 & 0.503 \\
\hline Tainan & Annan & 0.624 & 0.552 & 0.376 & 0.329 & 0.415 & 0.586 & 0.543 & 0.856 & 0.536 & 0.329 & 0.287 & 0.781 & 0.234 \\
\hline Chiayi & Budai & 0.620 & 0.507 & 0.274 & 0.423 & 0.610 & 0.536 & 0.396 & 0.275 & 0.316 & 0.261 & 0.405 & 0.238 & 0.473 \\
\hline Pingtung & Checheng & 0.613 & 0.474 & 0.436 & 0.239 & 0.579 & 0.581 & 0.222 & 0.212 & 0.306 & 0.474 & 0.435 & 0.225 & 0.182 \\
\hline Kaohsiung & Mituo & 0.608 & 0.360 & 0.352 & 0.270 & 0.480 & 0.174 & 0.352 & 0.395 & 0.319 & 0.362 & 0.546 & 0.079 & 0.230 \\
\hline Kaohsiung & Qieding & 0.580 & 0.383 & 0.361 & 0.355 & 0.453 & 0.264 & 0.360 & 0.439 & 0.364 & 0.360 & 0.628 & 0.238 & 0.299 \\
\hline Kaohsiung & Hunei & 0.569 & 0.390 & 0.360 & 0.389 & 0.492 & 0.228 & 0.366 & 0.436 & 0.339 & 0.366 & 0.561 & 0.546 & 0.299 \\
\hline Kaohsiung & Yong'an & 0.561 & 0.306 & 0.299 & 0.424 & 0.377 & 0.174 & 0.274 & 0.385 & 0.309 & 0.296 & 0.715 & 0.203 & 0.387 \\
\hline Kaohsiung & Linyuan & 0.552 & 0.433 & 0.416 & 0.404 & 0.360 & 0.361 & 0.572 & 0.640 & 0.431 & 0.412 & 0.806 & 0.458 & 0.268 \\
\hline Pingtung & Hengchun & 0.546 & 0.520 & 0.467 & 0.423 & 0.482 & 0.712 & 0.481 & 0.301 & 0.378 & 0.493 & 0.603 & 0.415 & 0.369 \\
\hline Kaohsiung & Luzhu & 0.542 & 0.425 & 0.449 & 0.388 & 0.414 & 0.276 & 0.679 & 0.520 & 0.414 & 0.459 & 0.698 & 0.506 & 0.265 \\
\hline Tainan & South District & 0.541 & 0.627 & 0.564 & 0.400 & 0.558 & 0.733 & 0.414 & 0.782 & $\begin{array}{l}0.670 \\
0.67\end{array}$ & 0.533 & 0.305 & 0.851 & 0.322 \\
\hline Pingtung & Manzhou & 0.537 & 0.449 & 0.440 & 0.429 & 0.579 & 0.489 & 0.238 & 0.207 & 0.301 & 0.481 & 0.542 & 0.333 & 0.417 \\
\hline Pingtung & Fangliao & 0.531 & 0.473 & 0.473 & 0.424 & 0.480 & 0.666 & 0.268 & 0.270 & 0.384 & 0.500 & 0.550 & 0.273 & 0.422 \\
\hline Kaohsiung & Zihguan & 0.531 & 0.356 & 0.417 & 0.411 & 0.339 & 0.305 & 0.394 & 0.465 & 0.385 & 0.427 & 0.966 & 0.162 & 0.299 \\
\hline Kaohsiung & Qijin & 0.520 & 0.430 & 0.583 & 0.305 & 0.558 & 0.299 & 0.287 & 0.448 & 0.526 & 0.600 & 0.465 & 0.418 & 0.229 \\
\hline Tainan & Jiangjun & 0.510 & 0.523 & 0.352 & 0.651 & $\begin{array}{l}0.598 \\
0.598\end{array}$ & 0.629 & 0.282 & $\begin{array}{l}0.332 \\
0.332\end{array}$ & 0.311 & 0.364 & $\begin{array}{l}0.400 \\
0.877\end{array}$ & $\begin{array}{l}.410 \\
0.383\end{array}$ & 0.646 \\
\hline Pingtung & Shizi & 0.503 & 0.255 & 0.239 & 0.616 & 0.259 & 0.285 & 0.256 & 0.191 & 0.300 & 0.221 & 0.592 & 0.380 & 0.680 \\
\hline Kaohsiung & Nanzi & 0.497 & 0.626 & 0.646 & 0.431 & 0.556 & 0.401 & 0.961 & 0.950 & 0.704 & 0.629 & 0.850 & 0.841 & 0.204 \\
\hline Tainan & Beimen & 0.496 & 0.428 & 0.296 & 0.689 & 0.497 & 0.456 & 0.302 & 0.297 & 0.331 & 0.286 & 0.311 & 0.579 & 0.831 \\
\hline Kaohsiung & Yancheng & 0.489 & 0.489 & 0.539 & 0.481 & 0.730 & 0.222 & 0.362 & 0.449 & 0.629 & 0.512 & 0.764 & 0.816 & 0.314 \\
\hline Pingtung & Mudan & 0.487 & 0.267 & 0.236 & 0.673 & 0.291 & 0.276 & 0.263 & 0.195 & 0.301 & 0.216 & 0.501 & 0.456 & 0.778 \\
\hline Pingtung & Linbian & 0.485 & 0.387 & 0.491 & 0.477 & 0.541 & 0.278 & 0.306 & 0.252 & 0.342 & 0.535 & 0.398 & 0.463 & 0.504 \\
\hline Tainan & Qigu & 0.484 & 0.469 & 0.356 & 0.682 & 0.552 & 0.444 & 0.414 & 0.339 & 0.307 & 0.370 & 0.631 & 0.324 & 0.783 \\
\hline Kaohsiung & Xiaogang & 0.476 & 0.569 & 0.688 & 0.402 & 0.400 & 0.432 & 0.950 & 0.946 & 0.592 & 0.717 & 0.748 & 0.722 & 0.220 \\
\hline Pingtung & Chunri & 0.476 & 0.308 & 0.233 & 0.734 & 0.352 & 0.345 & 0.227 & 0.189 & 0.314 & 0.209 & 0.236 & 0.305 & 0.989 \\
\hline Pingtung & Donggang & 0.473 & 0.370 & 0.527 & 0.459 & 0.312 & 0.422 & 0.444 & 0.368 & 0.615 & 0.501 & 0.549 & 0.468 & 0.429 \\
\hline Pingtung & Xinyuan & 0.467 & 0.365 & 0.412 & 0.598 & 0.436 & 0.327 & 0.294 & 0.309 & 0.320 & 0.439 & 0.607 & 0.275 & 0.673 \\
\hline Kaohsiung & Zuoying & 0.453 & 0.748 & 0.700 & 0.574 & 0.667 & 0.632 & 0.998 & 0.965 & 0.892 & 0.643 & 0.817 & 0.937 & 0.414 \\
\hline Pingtung & Jiadong & 0.438 & 0.466 & 0.414 & 0.746 & 0.630 & 0.415 & 0.318 & 0.252 & 0.310 & 0.445 & 0.600 & 0.454 & 0.861 \\
\hline Tainan & Anping & $\begin{array}{l}0.416 \\
0.416\end{array}$ & $\begin{array}{l}0.457 \\
0.457\end{array}$ & $\begin{array}{l}0.147 \\
0.669\end{array}$ & 0.518 & 0.489 & 0.380 & 0.404 & 0.554 & 0.523 & 0.712 & 0.229 & $\begin{array}{l}0.947 \\
0.969\end{array}$ & $\begin{array}{l}0.011 \\
0.499\end{array}$ \\
\hline Pingtung & Fangshan & 0.415 & 0.355 & 0.476 & 0.666 & 0.507 & 0.269 & 0.251 & 0.197 & 0.304 & 0.527 & 0.238 & 0.189 & 0.911 \\
\hline Tainan & Central West District & 0.405 & 0.673 & 0.739 & 0.616 & 0.786 & 0.589 & 0.538 & 0.641 & 0.805 & 0.719 & 0.506 & 0.934 & 0.574 \\
\hline Kaohsiung & Gushan & 0.390 & 0.626 & 0.727 & 0.637 & 0.622 & 0.352 & 0.892 & 0.918 & 0.788 & 0.710 & 0.671 & 0.861 & 0.574 \\
\hline Kaohsiung & Qianzhen & 0.348 & 0.681 & 0.784 & 0.728 & 0.599 & 0.505 & 0.994 & 0.967 & 0.789 & 0.783 & 0.587 & 0.877 & 0.737 \\
\hline \multicolumn{2}{|r|}{ Average } & 0.509 & 0.467 & 0.459 & 0.498 & 0.504 & 0.425 & 0.449 & 0.463 & 0.450 & 0.462 & 0.561 & 0.488 & 0.480 \\
\hline
\end{tabular}

Note: The higher the index, the higher the vulnerability. 


\subsection{Selection of Indicators}

A five-point Likert scale questionnaire was adopted in the modified Delphi method [34] and questionnaire surveys were conducted on 15 scholars selected according to their profession and experience. Of these, 11 respondents replied three times (Appendix A). A score of 1 indicates strong disagreement with an indicator, while a score of 5 means strong agreement with an indicator. When the indicator averaged greater than 4 , an indicator was accepted after achieving common consensus and was subsumed in the indicator group directly on the basis of the results of the surveys. If the average was less than 3.5, an indicator was omitted. If the mean value was between 3.5 and 3.9, the indicator progressed to the next round [35]. The respondents also added one indicator after the first round.

A total of 29 indicators was selected in this study (Appendix A) on the basis of the results of the questionnaires and available data [36-39]. If the data of an indicator was unavailable, it was deleted.

\subsection{Uniform Transformation of Indicator Variables}

By means of a logic dichotomy, indicators were categorized into positive or negative values and then were processed in accordance with the principle of uniform transformation of indicator variables. If the original numerals were high and positively correlated with vulnerability, then the uniform score " $\mathrm{p}$ " was recognized as the probability of its standard normal curve and its homologous standard normalized $Z$ score. If the indicator was negatively correlated with vulnerability, the evaluating score was " $1-p$ ". Therefore, a higher $p$ score indicates higher vulnerability.

\subsection{Allocation of Weight}

The paired comparison approach was used to establish a hierarchical structure for a gradual analysis problem in the analytic hierarchy process method. The relative relation of indicators was evaluated by respondents for determining the weight of each indicator [40,41]. In the questionnaire, the relative importance can be divided into nine levels. Therefore, the levels of importance differ. By means of a consistency index (CI), this study examined the consistency of the overall hierarchy structure [42], for which the calculation formula is as follows:

$$
\mathrm{CI}=\left(\lambda_{\max }-n\right) /(n-1)
$$

where $\lambda_{\max }$ is the maximum eigenvalue of $\mathrm{A}$. The best situation is $\mathrm{CI}<0.1$ [40]. A paired comparison of the element and criteria of each level on the basis of importance was completed after the consistency test, and then we defined the importance and weight of each indicator (Figure 1).

\subsection{Aggregation and Visualization}

The aggregative index of dimension $\mathrm{Si}$ is defined by:

$$
S_{i}(t)=\sum_{j=1}^{m_{i}} S_{i j}(t) \times W_{i j}
$$

where $S_{i j}(t)$ is the value of the indicator and $W_{i j}$ is the weight value of the indicator.

Finally, the Super GIS was employed to visualize the distinct levels between these 35 coastal townships.

\section{Results}

\subsection{Significant Criteria and Indicators}

For susceptibility (Q1), the criterion of social structure (C1) weighted the highest at 0.418 , and economic construction (C3) the lowest at 0.129 . For the indicators, the ratio of solitary elders (I8) weighted the highest at 0.032 , and the ratio of females the lowest (I5) at 0.005 , suggesting that solitary elders are most exposed to climate changes and should be prioritized in precautionary actions 
(Figure 1). For resistance (Q2), the criterion of precautionary facilities (C6) weighted the highest at 0.772 , and medical relief (C5) the lowest at 0.228 . In terms of indicators, the amount of water rescue equipment (I17) weighted the highest (0.101), while the number of hospital beds (I15) scored the lowest weight (0.016), indicating that water rescue equipment is essential in resisting coastal disasters (Figure 1). Finally, for resilience (Q3), disaster awareness (C9) is the criterion with the highest weight at 0.647 , while level of education (C8) scored the lowest (0.154). For the indicators, disaster prevention awareness (I28) weighted the highest at 0.108 , and the ratio of the illiterate population the lowest (I5) at 0.002. This implies that raising awareness should be emphasized, as shown in Figure 1.

\subsection{Susceptibility}

Generally, the higher the susceptibility index, the more vulnerable the society. Based on the analyzed results presented in Table 1, the most exposed regions are located in Zuoying in Kaohsiung (0.748), Qianzhen in Kaohsiung (0.681), the West Central District of Tainan (0.673), the South District of Tainan (0.627), and Nanzi in Kaohsiung (0.626).

The five lowest are Shizi Township in Pingtung (0.255), Mudan Township in Pingtung (0.267), Yong'an District in Kaohsiung (0.306), Chunri Township in Pingtung (0.308), and Fangshan Township in Pingtung (0.355) (Figure 2). Yancheng in Kaohsiung weighted the highest (0.730) in terms of social structure (C1), and Shizi Township in Pingtung the lowest (0.259). For underprivileged groups (C2), the highest is Dongshi Township in Chiayi (0.843), and the lowest is Mituo District (0.174) and Yongan District in Kaohsiung (0.174). For economic construction (C3), the highest index is Zuoying in Kaohsiung (0.998), and the lowest is the Checheng Township in Pingtung (0.222). For movables and immovables (C4), the highest index is Qianzhen in Kaohsiung (0.967), and the lowest is Shizi Township in Pingtung (0.191) (Table 1).

\subsection{Resistance}

Generally, the vulnerability of society decreases as the resistance index increases. The results are demonstrated in Figure 3. It was found that the five townships ranked lowest in terms of resistance are located in Chunri Township in Pingtung (0.233), Mudan Township in Pingtung (0.236), Shizi Township in Pingtung (0.239), Budai Township in Chiayi (0.274), and Dongshi Township in Chiayi (0.283). The five townships ranked highest for resistance are situated in Qianzhen in Kaohsiung (0.784), the West Central District in Tainan (0.739), Gushan in Kaohsiung (0.727), Zuoying in Kaohsiung (0.700), and Xiaogang in Kaohsiung (0.688). At the criterion level, Zuoying in Kaohsiung ranks the highest (0.892) for medical relief (C5), and Shizi Township in Pingtung the lowest (0.300). For precautionary facilities (C6), the highest and lowest ranks are Qianzhen in Kaohsiung (0.783) and Mudan Township in Pingtung (0.216), respectively, as presented in Table 1.

\subsection{Resilience}

Note that the higher the resilience index, the less vulnerable the society. Figure 4 depicts the results for the degree of resilience of the southwest coastal areas. The five lowest ranked townships in terms of resistance are located in the Checheng Township in Pingtung (0.239), Mituo in Kaohsiung (0.270), Qijin in Kaohsiung (0.305), Annan in Tainan (0.329), and Qieding in Kaohsiung (0.355). On the other hand, we notice that the five townships ranked highest are the Jiadong Township in Pingtung (0.746), Chunri Township in Pingtung (0.734), Qianzhen in Kaohsiung (0.728), Beimen District in Tainan (0.689), and Qigu District in Tainan (0.682). At the criterion level, Zihguan in Kaohsiung ranks the highest (0.966) for economic structure (C7), and Anping District in Tainan ranks the lowest (0.229). In Table 1, it is interesting to note that Anping also ranks the highest (0.969) in terms of the level of education (C8), while Dongshi Township in Chiayi ranks the lowest (0.108). As for the disaster awareness indicator (C9), the highest and lowest ranked are Fangshan Township in Pingtung (0.911) and Checheng Township in Pingtung (0.182), respectively. 


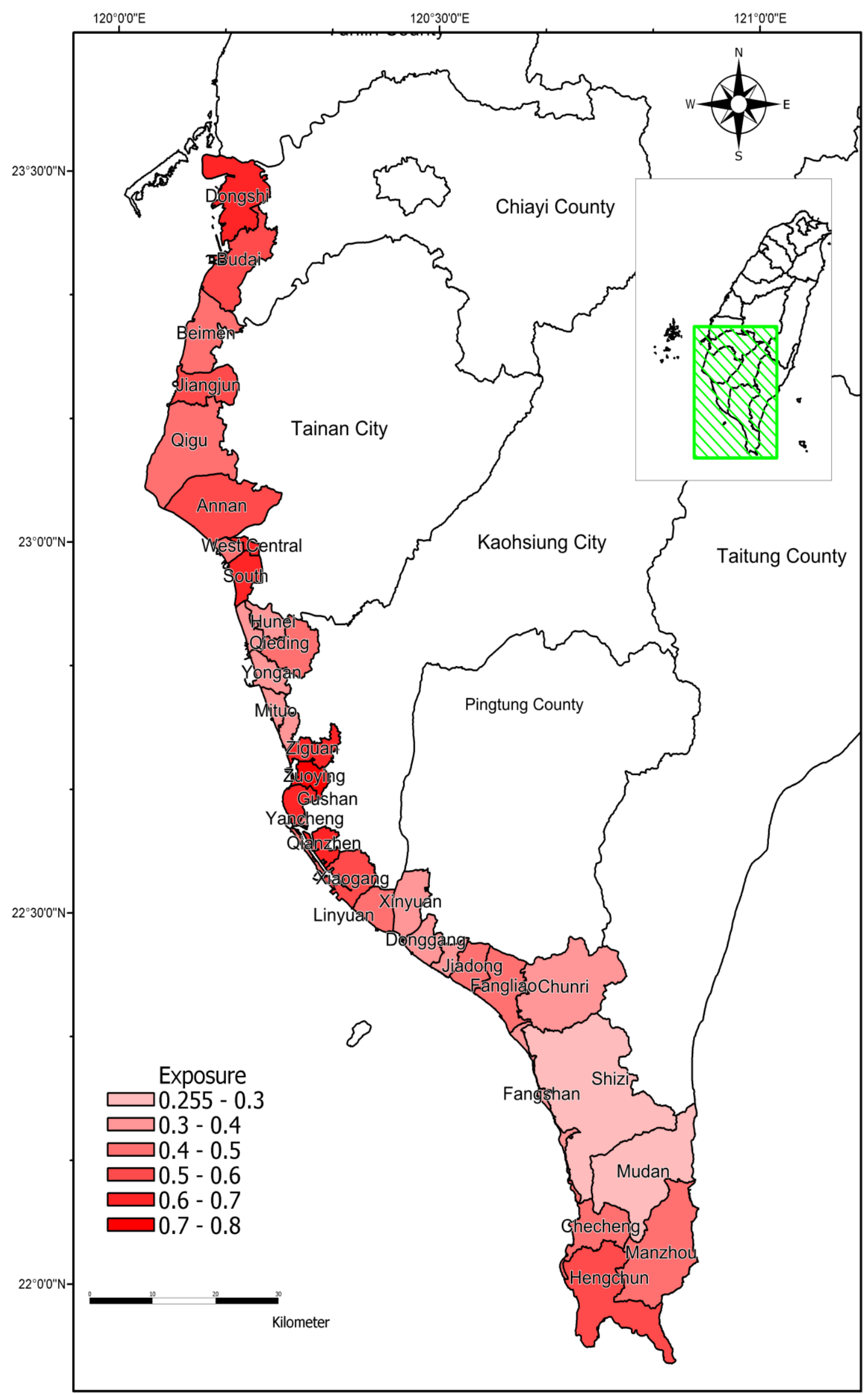

Figure 2. Degree of susceptibility of townships in southwest Taiwan. 


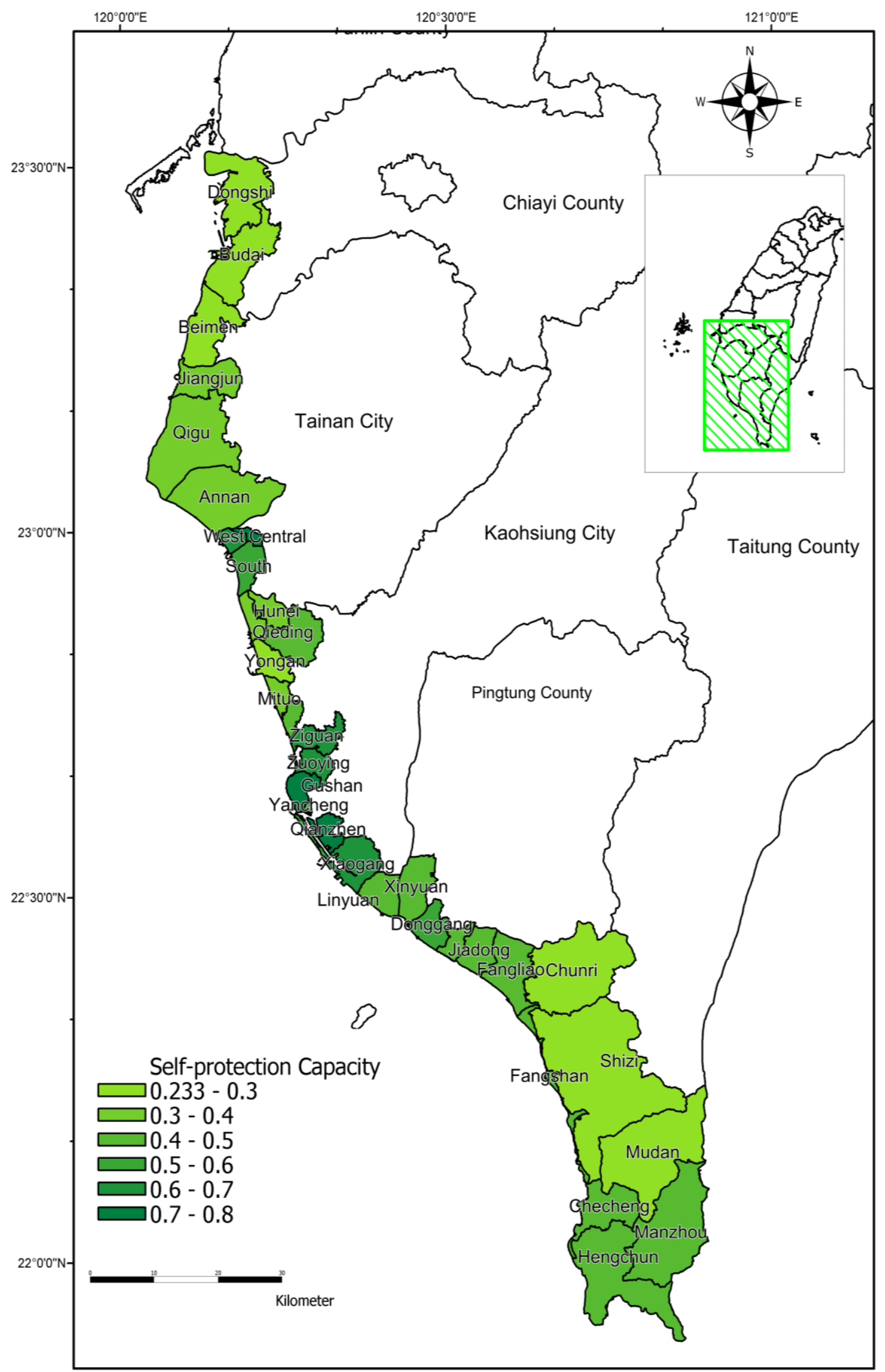

Figure 3. Degree of resistance of townships in southwest Taiwan. 


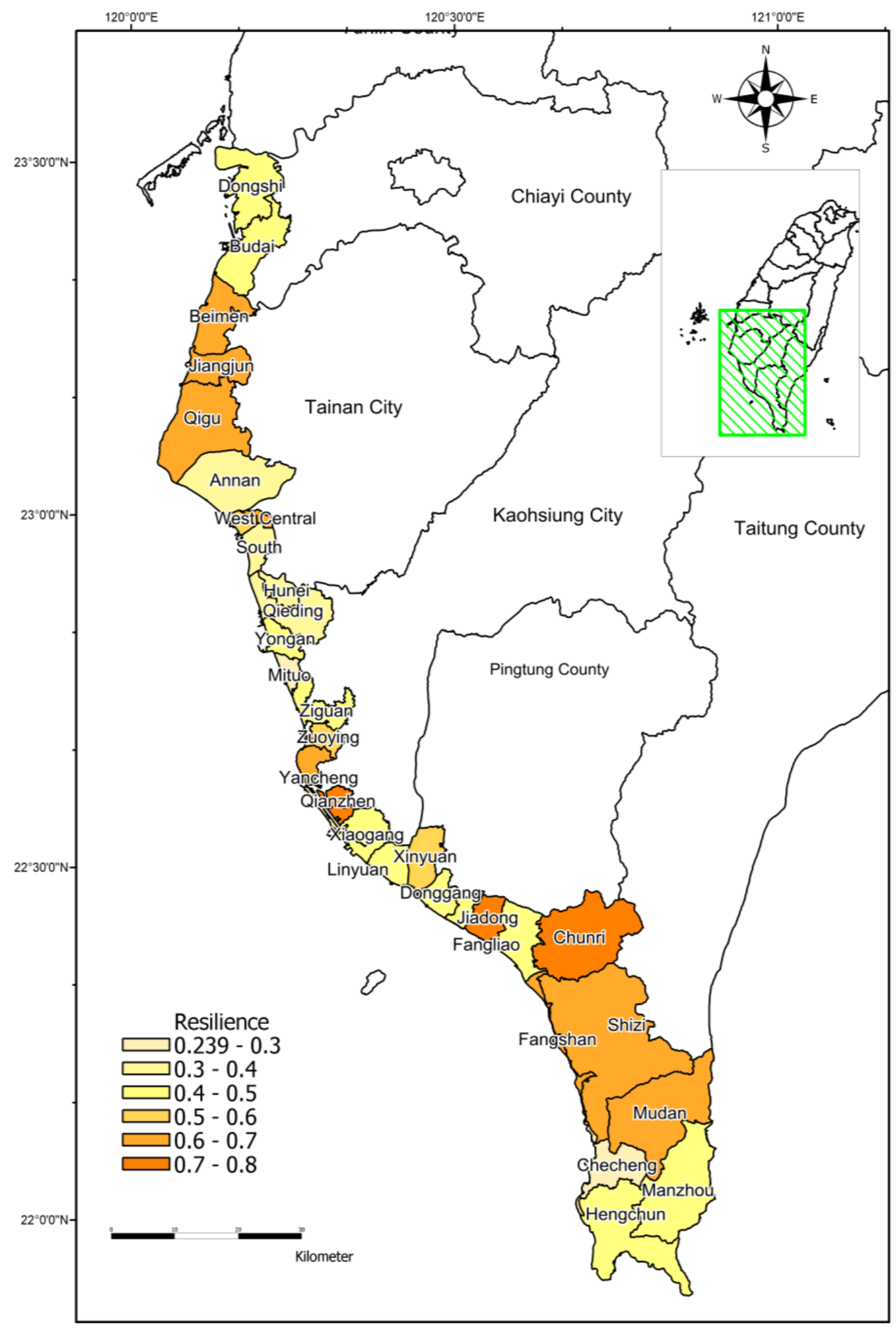

Figure 4. Degree of resilience of townships in southwest Taiwan.

\subsection{Social Vulnerability}

A higher social vulnerability index results in a more vulnerable township. The results for vulnerability are presented in Figure 5. We note that Dongshi Township in Chiayi is the most vulnerable (0.641), because it ranks relatively lower for resistance (fifth lowest) and resilience (12th lowest), but higher for 
susceptibility (seventh highest). The social vulnerability of the Annan District in Tainan is ranked second highest (0.624), because it ranks fourth lowest for resilience and ninth highest for susceptibility. Following this are Budai Township in Chiayi (0.620), Checheng Township in Pingtung (0.613), and Mituo in Kaohsiung (0.608), as they rank in the lowest five for resistance and resilience. The five townships with the lowest vulnerability in Taiwan's coastal regions are Qianzhen in Kaohsiung (0.348), Gushan in Kaohsiung (0.390), the Central West District of Tainan (0.405), Fangshan Township in Pingtung (0.415), and Anping District in Tainan (0.416), as shown in Figure 5 and Table 1.

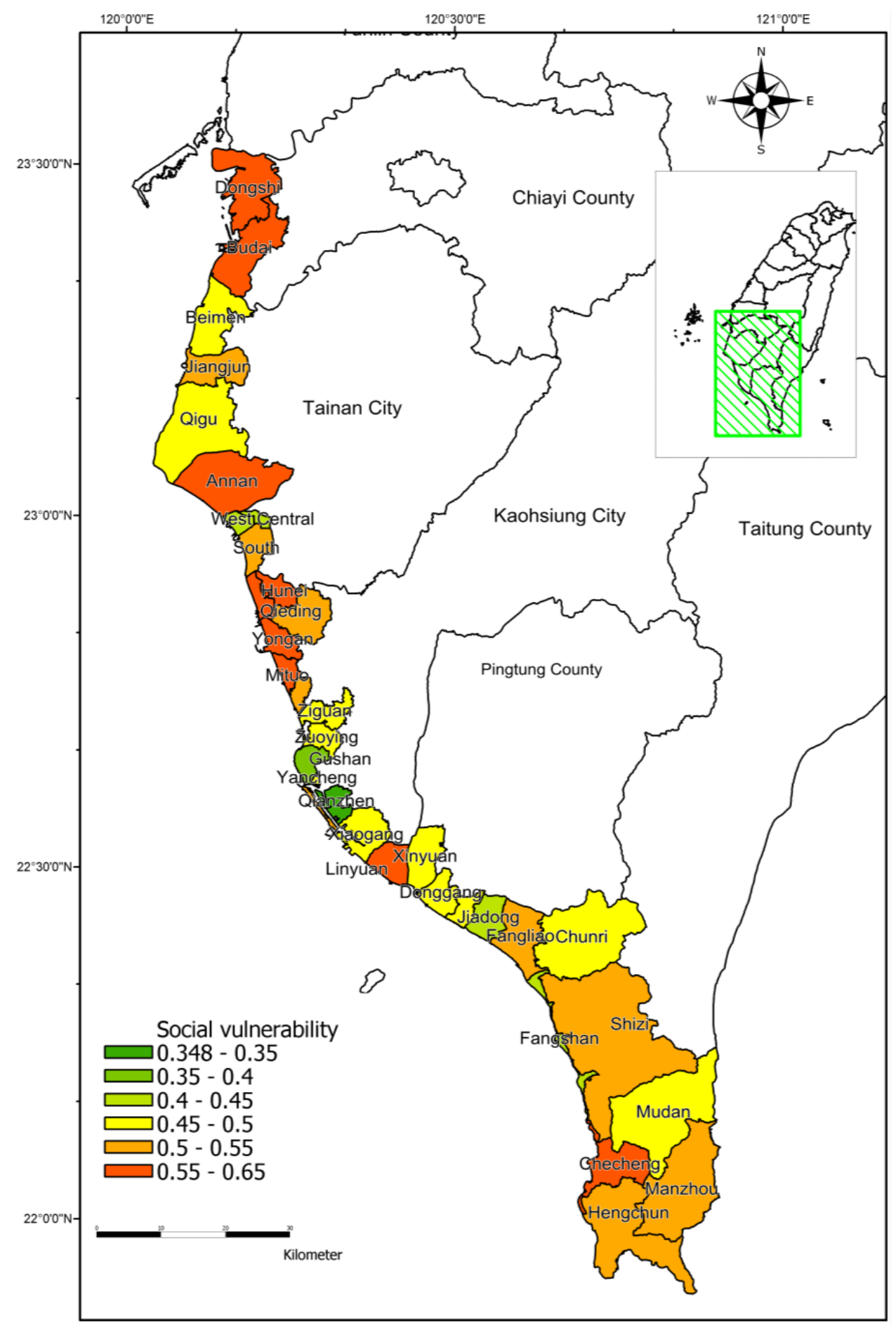

Figure 5. Degree of social vulnerability of townships in southwest Taiwan. 


\section{Discussion}

As shown by the coastal vulnerability assessment at the township level, Chiu (2010) indicated that the west coast is more vulnerable than the east coast, as is the south coast compared to the north coast [43]. The Yancheng and Qijin Districts are the most vulnerable areas [43]. Chang (2011) assessed that coastal damage is mostly caused by the increased frequency and intensity of typhoons and the rising sea level [44]. Therefore, social vulnerability is the most significant aftermath of natural disasters, which is demonstrated by the coping mechanisms and resilience of different social groups. For example, this study demonstrates that while municipalities and townships in Chiayi are prone to flooding, they are less vulnerable because their communities are more resistant to disasters. While no one is exempt from natural disasters, the underprivileged are the group most at risk because of their lack of preparedness for such emergencies, poor housing conditions, and lack of access to resources consequent to isolation from society and policy-making. The prevention of natural disasters and relief from the resultant damage include hydrological and climate conditions, as well as socioeconomic and political factors [45-47]. Understanding influential factors when struck by a natural disaster is crucial to the development of effective coping strategies [27].

The southwest coastal area suffers most from typhoons, heavy rain, land subsidence, seawater in-welling, and poor drainage. Li (2009) revealed that the Changhua, Yunlin, Tainan, and Pingtung Townships are the most vulnerable on Taiwan's southwest coast [39]. For the socioeconomic dimension, Hsu et al. (2001) suggest that the Anping District in Tainan is highly vulnerable, because of its high population density [28]. It is evident that the present study differs from $\mathrm{Li}$ (2009) and Hsu et al. (2011) in the selection of indicators [28,48]. Moreover, the scope also differs from a study by Li (2009) which focused on the municipality level, as this investigation focuses on the township level [48]. By selecting three dimensions, nine criteria, and 29 indicators, and allocating weights accordingly, this study better assesses social vulnerability than the preceding two studies mentioned. The difference is that the present study employed the modified Delphi method to select indicators, and used the analytic hierarchy process to allocate weights. This method better clarifies the hierarchy of precautionary measures. Furthermore, the calculation of weights quantifies vulnerability, and thus provides a tangible illustration of regional differences.

As shown by the analytic hierarchy process (AHP) analysis, these results demonstrate that most experts emphasize that the existing social structure may significantly contribute to exposure to climate change in the coastal areas of Taiwan. Furthermore, increasing precautionary facilities and disaster awareness were prioritized to decrease socioeconomic vulnerability to climate change. In addition, the weight of the resistance index is greater than the weights of the resilience and susceptibility indexes, respectively, implying that the latter two are more influential. The top five vulnerable districts do not overlap with the five most exposed areas, although they are the least resistant or resilient. Therefore, both resistance and resilience are more influential and should be addressed when decreasing vulnerability. Accordingly, coastal areas need more resources to improve their capacities for resistance and resilience when designing relevant strategies. Furthermore, Hsu et al. estimate coastal hazards using three dimensions [28]: (1) artificial facilities (relative ratio of seawall length, relative ratio of seawall height, relative ratio of tidal gate); (2) environmental geography (elevation, slope, tidal range, rate of land subsidence, rate of coastal erosion, and land usage); and (3) socioeconomics (population density, relative value of education, rate for providing support to the elderly, and enterprise return). For the environmental geography dimension, the most vulnerable are the townships of Dongshi and Budai of Chiayi, Qigu of Tainan, and Xinyuan, Linbian, and Jiadong of Pingtung. Comparing the results from Hsu et al. and the present study, Dongshi and Budai of Chiayi are exceptional, as they are vulnerable in both dimensions. To adapt the impacts of climate change, buffer zones should be planned. The adaptation could dissipate wave energy and allow a wide space for shoreline changes in different wave climates. In the present social vulnerability assessment, decision-makers not only access physical vulnerability such as precipitation, terrain, and typhoons, but also measure vulnerabilities in 
terms of economic scale and resilient capacity after natural disasters. This information is beneficial in terms of improving the allocation of public resources.

Finally, previous studies [19,22-26,48,49] usually employed quantified indicators in the assessment of social vulnerability. However, this approach has some limitations, including the impossibility of quantifying certain factors such as social capital, and the unfeasibility of evaluating vulnerability [50]. In addition, database availability is a major limitation in the use of indicators. The present study employs the analytic hierarchy process to calculate the weights of each indicator. This enhances the understanding of the importance various stakeholders associate with each indicator. However, this is also limiting in some aspects. For example, it relies mostly on second-hand data, with the exception of information collected through the questionnaires. Given the limited availability and accuracy of data, the assessment of social vulnerability may not be completely accurate. Moreover, this study only presents the average at the township level, which is not applicable to the household or individual levels. The scale of indicator selection may be purposely oriented [46,47]. Indicators at these levels could reflect practical situations [51]. Future investigations could be conducted regarding the vulnerability of households or individuals.

\section{Conclusions}

This study employed the fuzzy Delphi method and analytic hierarchy process to develop nine criteria and 26 indexes to evaluate the susceptibility, resistance, resilience, and social vulnerability of 35 townships in the southwest coastal area of Taiwan. The study indicated that the five most vulnerable districts are the Dongshi Township in Chiayi (0.641), Annan District in Tainan (0.624), Budai Township in Chiayi (0.620), Checheng Township in Pingtung (0.613), and Mituo District in Kaohsiung (0.608). These results (Table 1) demonstrate that a susceptible social structure and underprivileged groups are factors with the most potential for vulnerability to climate change in Taiwan's southwest coastal area. Furthermore, the five most vulnerable districts do not match the five most susceptible ones; therefore, the resistance and resilience indexes are more influential than the susceptibility index. The most significant criteria were identified as precautionary facilities (0.308), disaster awareness (0.233), and social structure (0.101). Social vulnerability is part of vulnerability in the broad sense, corresponding to non-social vulnerability. Social vulnerability comprises three dimensions. Resistance is the ability to secure one's properties, as calculated through an assessment of an individual/household member's awareness of disasters and precautionary actions. As awareness is intangible, the variables are disaster experience, age, and gender. In contrast, this study conducted a sample survey in 35 regions on the awareness of climate change, preparedness against disasters, and psychological vulnerability of local residents. These three factors are more relevant to disaster awareness in terms of conducting education and disaster drills to promote awareness and enhance preparedness. Consequently, the authors concur that the vulnerability indicator is a practical and useful tool to increase decision-makers' understanding of physical vulnerability and resilient capacity to the impacts of climate change. Furthermore, it is beneficial for improving the allocation of resources and reducing risks.

Acknowledgments: The authors would like to thank the reviewers for their useful comments on this paper. Support and feedback from the staff of the Center of Marine Affairs, National Kaohsiung Marine University, Taiwan, is also much appreciated. This research was made possible with financial support from the Ministry of Science and Technology (MOST102-2410-H-022-006) and the Water Resource Agency (MOEAWRA1000075).

Author Contributions: In this paper, Chin-Cheng Wu designed the research programs, provided the GIS software technology, analyzed the results, and wrote the Introduction as well as the Methodology and Results sections. Hao-Tang Jhan, Tai-Wen Hsu, and Kuo-Huan Ting conducted data collection and the interview survey, and analyzed the results of the survey. Meng-Tsung Lee and Heng-Chieh Tsai carried out data collection, and formulated and analyzed the figures using GIS software. Wen-Hong Liu conceptualized and developed the research framework and wrote the Discussion and Conclusions sections.

Conflicts of Interest: The authors declare no conflict of interest. 


\section{Appendix A}

Table A1. Results of the Modified Delphi Questionnaire of Candidate Indicators.

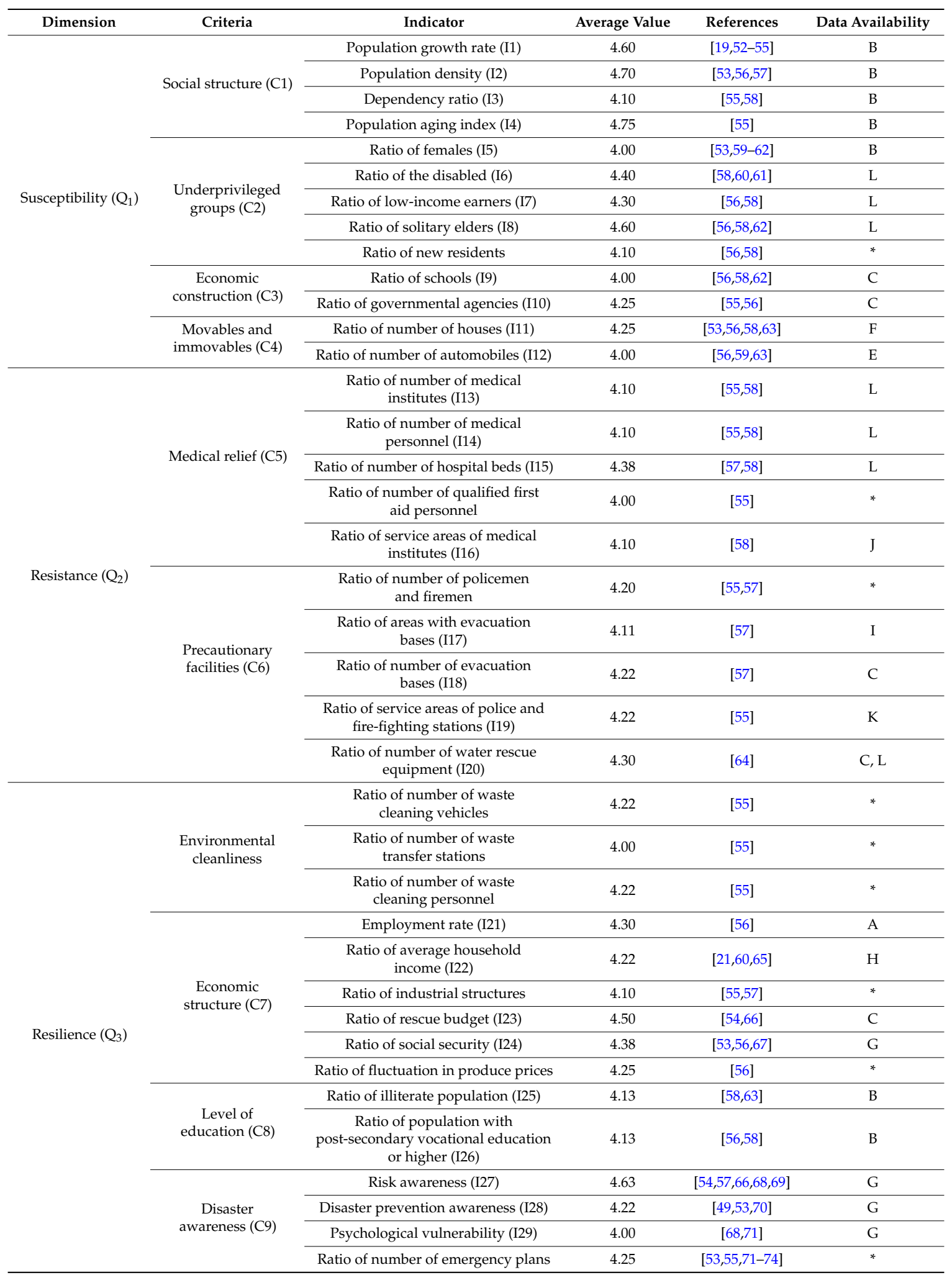

Note: A: National Statistics; B: Statistical Yearbook of Interior; C: Township Office, District Office; D: Township Office, District Office (10\% of budget); E: Motor Vehicles Office; F: Hospitality website; G: Questionnaire; H: National Taxation Bureau; I: Ministry of Health and Welfare; J: National Police Agency, K: National Fire Agency; L: Local Government Statistical Yearbook; *: lack of data. 


\section{References}

1. Poortinga, W.; Spencec, A.; Whitmarshb, L.; Capstickb, S.; Pidgeonb, N.F. Uncertain climate: An investigation into public skepticism about anthropogenic climate change. Glob. Environ. Chang. 2011, 21, 1015-1024. [CrossRef]

2. Urwin, K.; Jordan, A. Does public policy support or undermine climate change adaptation? Exploring policy interplay across different scales of governance. Glob. Environ. Chang. 2008, 18, 180-191. [CrossRef]

3. Tribbia, J.; Moser, S.C. More than information: What coastal managers need to plan for climate change. Environ. Sci. Policy 2008, 11, 315-328. [CrossRef]

4. Monirul, M.; Mirza, Q. Climate change and extreme weather events: Can developing countries adapt? Clim. Policy 2003, 3, 233-248.

5. Byrne, J.; Inniss, V. Island sustainability and sustainable development in the context of climate change. In Sustainable Development for Island Societies: Taiwan and the World; Asia-Pacific Research Program, Academia Sinica and SARCS Secretariat; Hsiao, H.H.M., Liu, C.H., Tsai, H.M., Eds.; National Central University Press: Taipei, Taiwan, 2002; pp. 3-29.

6. Intergovernmental Panel on Climate Change (IPCC). Managing the risks of extreme events and disasters to advance climate change adaptation. In A Special Report of Working Groups I and II of the Intergovernmental Panel on Climate Change; Field, C.B., Barros, V., Stocker, T.F., Qin, D., Dokken, D.J., Ebi, K.L., Mastrandrea, M.D., Mach, K.J., Plattner, G.K., Allen, S.K., Eds.; Cambridge University: Cambridge, UK; New York, NY, USA, 2012.

7. Cai, F.; Su, X.; Liu, J.; Li, B.; Lei, G. Coastal erosion in China under the condition of global climate change and measures for its prevention. Prog. Nat. Sci. 2009, 19, 415-426. [CrossRef]

8. Dow, K.; Downing, T.E. The Atlas of Climate Change; Earthscan: London, UK, 2007.

9. McGranahan, G.; Balk, D.; Anderson, B. The rising tide: Assessing the risks of climate change and human settlements in low-elevation coastal zones. In Adapting Cities to Climate Change; Bicknell, J., Dodman, D., Satterthwaite, D., Eds.; Earthscan: London, UK, 2009.

10. Cutter, S.L.; Boruff, B.J.; Shirley, W.L. Social vulnerability to environmental hazards. Soc. Sci. Q. 2003, 84, 242-261. [CrossRef]

11. Intergovernmental Panel on Climate Change (IPCC). Climate Change 2007: Impacts, Adaptation and Vulnerability; Contribution of Working Group II to the Fourth Assessment Report of the Intergovernmental Panel on Climate Change; Cambridge University Press: Cambridge, UK, 2007.

12. Smit, B.; Pilifosova, O. Adaptation to climate change on the context of sustainable development and equity. In Climate Change 2001: Impacts, Adaptation, and Vulnerability; McCarthy, J.J., Canziani, O.F., Leary, N.A., Dokken, D.J., White, K.S., Eds.; Cambridge University Press: Cambridge, UK, 2001; pp. 879-912.

13. Wilbanks, T.; Lankao, P.R. Industry, settlement and society. In Climate Change 2007: Impacts, Adaptation and Vulnerability; Parry, M., Canziani, O., Palutikof, J., van der Linden, P., Hanson, C., Eds.; Cambridge University Press: Cambridge, UK, 2007; pp. 358-390.

14. Timmerman, P. Vulnerability, Resilience and the Collapse of Society: A Review of Models and Possible Climatic Applications; University of Toronto: Toronto, ON, Canada, 1981.

15. Adger, W.N.; Kelly, P.M. Social vulnerability to climate change and the architecture of entitlements. Mitig. Adapt. Strateg. Glob. Chang. 1999, 4, 253-266. [CrossRef]

16. Cutter, S.L.; Mitchell, J.T.; Scott, M.S. Revealing the vulnerability of people and places: A case study of Georgetown County, South Carolina. Ann. Assoc. Am. Geogr. 2000, 90, 713-737. [CrossRef]

17. Hinkel, J.; Klein, R.J.T. Integrating knowledge to assess coastal vulnerability to sea-level rise: The development of the DIVA tool. Glob. Environ. Chang. 2009, 19, 384-395. [CrossRef]

18. Wisner, B.; Blaikie, P.; Cannon, T.; Davis, I. At Risk: Natural Hazards, People's Vulnerability and Disasters, 2nd ed.; Routledge: New York, NY, USA, 2004.

19. Cutter, S.L. The vulnerability of science and the science of vulnerability. Ann. Assoc. Am. Geogr. 2003, 93, 1-12. [CrossRef]

20. White, G.F. Human Adjustment to Floods; Paper No. 29; Department of Geography Research, The University of Chicago: Chicago, IL, USA, 1945.

21. White, G.F.; Haas, J. Assessment of Research on Natural Hazards; MIT Press: Cambridge, MA, USA, 1975.

22. Adger, W.N. Vulnerability. Glob. Environ. Chang. 2006, 16, 268-281. [CrossRef] 
23. Nicholls, R.J.; Wong, P.P. Coastal system and low-lying areas. In Climate Change 2007: Impacts, Adaptation and Vulnerability; Parry, M., Canziani, O., Palutikof, J., van der Linden, P., Hanson, C., Eds.; Cambridge University Press: Cambridge, UK, 2007; pp. 316-357.

24. Yasuhara, K.; Komine, H.; Murakami, S.; Chen, G.; Mitani, Y.; Duc, D.M. Effects of climate change on geo-disasters in coastal zones and their adaptation. Geotext. Geomembr. 2012, 30, 24-34. [CrossRef]

25. Klein, R.J.T.; Nicholls, R.J.; Thomalla, F. Resilience to natural hazards: How useful is this concept? Environ. Hazards 2003, 5, 35-45. [CrossRef]

26. Cutter, S.L.; Emrich, C.T.; Webb, J.J.; Morath, D. Social Vulnerability to Climate Variability Hazards: A Review of the Literature; Hazards and Vulnerability Research Institute, Department of Geography University of South Carolina Columbia Press: Columbia, SC, USA, 2009.

27. Tapsell, S.; McCarthy, S.; Faulkner, H.; Alexander, M. Social Vulnerability to Natural Hazards; Flood Hazard Research Centre, Middlesex University: London, UK, 2010.

28. Hsu, T.W.; Yu, P.S.; Hwuang, C.J.; Lan, Y.J.; Lin, J.Y.; Chen, S.T.; Yang, T.C.; Lu, G.Y.; Chang, K.S.; Chen, C.C.; et al. Strengthening Sustainable Water Resources Utilization and Adaptive Capacity to Climate Change; Water Resources Agency, Ministry of Economic Affairs: Taipei, Taiwan, 2011. (In Chinese)

29. Singh, A.; Pathirana, S.; Shi, H. Assessing Coastal Vulnerability: Developing a Global Index for Measuring Risk. UNEP, 2005. Available online: http://www.unep.org/publications/search/pub_details_s.asp?ID= 3752 (accessed on 2 January 2016).

30. Water Resources Agency of the Ministry of Economic Affairs. White Paper on Water Resources; Water Resources Agency of the Ministry of Economic Affairs: Taipei, Taiwan, 2006. (In Chinese)

31. Li, W.S.; Yeh, K.C.; Lin, C.C.; Shieh, C.L.; Wen, J.C.; Yeh, Y.L.; Hsieh, L.S.; Chen, L.K.; Li, H.C.; Wang, Y.W. Disaster Survey and Analysis of Morakot Typhoon; National Science and Technology Center for Disaster Reduction: Taipei, Taiwan, 2009. (In Chinese)

32. Adger, W.N.; Brooks, N.; Bentham, G.; Agnew, M.; Eriksen, S. New Indicators of Vulnerability Adaptive Capacity; Tyndall Centre for Climate Change Research Technical Report 7; Tyndall Centre for Climate Change Research: Manchester, UK, 2004.

33. Vincent, K. Creating an Index of Social Vulnerability to Climate Change in Africa; Tyndall Centre for Climate Research Working Paper No. 56; University of East Anglia: Norwich, UK, 2004.

34. Murry, J.W.; Hammons, J.O. Delphi: A versatile methodology for conducting qualitative research. Rev. High. Educ. 1995, 18, 423-436.

35. Dixon, E.C.; Maddern, G.; Sutherland, F.; Hemming, A.; Wei, A.; Sherman, M.; Moore, M.; Mckay, A.; Urbach, D.; Labrie, M.; et al. Development of quality indicators of care for patients undergoing hepatic resection for metastatic colorectal cancer using a Delphi process. J. Surg. Res. 2009, 156, 32-38. [CrossRef] [PubMed]

36. Füssel, H.M. How inequitable is the global distribution of responsibility, capability, and vulnerability to climate change: A comprehensive indicator-based assessment. Globe Environ. Chang. 2010, 20, 597-611. [CrossRef]

37. Birkmann, J. Measuring Vulnerability to Natural Hazards: Towards Disaster Resilient Societies; TERI Press: New Delhi, India, 2006.

38. Moss, R.H.; Brenkert, A.L.; Malone, E.L. Vulnerability to Climate Change: A Quantitative Approach; US Department of Energy, Battelle Institute: Washington, DC, USA, 2001.

39. Li, Y.J. Social vulnerability indicator as a sustainable planning tool. Environ. Impact Assess. Rev. 2014, 44, $31-42$.

40. Saaty, T.L. That is not the analytic hierarchy process: What the AHP is and what it is not. J. Multi-Criteria Decis. Anal. 1997, 6, 324-335. [CrossRef]

41. Nydick, R.; Hill, R. Using the Analytical Hierarchy Process to Structure the Supplier Selection Procedure. Int. J. Purch. Mater. Manag. 1992, 28, 31-36.

42. Teng, C.Y. Project Evaluation: Methods and Applications, 2nd ed.; The Research Centre of Logistics Planning and Management Press: Taipei, Taiwan, 2005.

43. Chiu, S.Y. A Study on Establishment and Application of Coastal Vulnerability Indicators in Taiwan. Master's Thesis, National Taiwan Ocean University, Keelung, Taiwan, 2010. (In Chinese)

44. Chang, S.W. The Analysis of Coastal Vulnerability in Taiwan Area under Climate Change. Master's Thesis, National Taiwan Ocean University, Keelung, Taiwan, 2011. (In Chinese) 
45. Polsky, C.R.; Neff, R.; Yarnal, B. Building comparable global change vulnerability assessments: The vulnerability scoping diagram. Glob. Environ. Chang. 2007, 17, 472-485. [CrossRef]

46. Ahsan, M.N.; Warner, J. The socioeconomic vulnerability index: A pragmatic approach for assessing climate change led risks-A case study in the south-western coastal Bangladesh. Int. J. Dis. Risk Reduct. 2014, 8, 32-49. [CrossRef]

47. Hinkel, J. Indicators of vulnerability and adaptive capacity: Towards a clarification of the science-policy interface. Globe Environ. Chang. 2011, 21, 198-208. [CrossRef]

48. Li, H.C.; Yang, H.H.; Liao, K.M.; Shaw, D.G. Establishment of Social Vulnerability Indicators for Flooding. J. Archit. Plan. 2009, 10, 163-182. (In Chinese)

49. King, D.; MacGregor, C. Using social indicators to measure community vulnerability to natural hazards. Aust. J. Emerg. Manag. 2000, 15, 52-57.

50. Rygel, L.; O'Sullivan, D.; Yarnal, B. A method for constructing a social vulnerability index: An application to hurricane storm surges in a developed country. Mitig. Adapt. Strategies Glob. Chang. 2006, 11, 741-764. [CrossRef]

51. Zahran, S.; Brody, S.D.; Vedlitz, A.; Grover, H.; Miller, C. Vulnerability and capacity: Explaining local commitment to climate change policy. Environ. Plan. C Govern. Policy 2008, 26, 544-562. [CrossRef]

52. Bollin, C.; Hidajat, R. Community-Based Disaster Risk Index: Pilot Implementation in Indonesia. In Measuring Vulnerability to Natural Hazards_-Towards Disaster Resilient Societies; Birkmann, J., Ed.; UNU-Press: Tokyo, Japan; New York, NY, USA; Paris, France, 1998; pp. 271-289.

53. Kuo, Y.L.; Xiao, D.J.; Lin, Y.L.; Hsieh, H.W.; Chang, M.C. Review of Vulnerability of Natural Disasters and Factors of Social Vulnerability; National Science and Technology Center for Disaster Reduction: New Taipei, Taiwan, 2009. (In Chinese)

54. Chen, L.Y. The Assessment of Typhoon and Flood Vulnerabilities in Ta-Chia River Basin: The Application of Analytic Network Process; Department of Real Estate \& Built Environment, College of Public Affairs, National Taipei University: New Taipei, Taiwan, 2009. (In Chinese)

55. Chen, Y.C.; Li, C.H.; Su, W.R.; Tsai, Y.F. Using AHP to map flood vulnerability of the Ping-Tung coastal area. J. Taiwan Water Conserv. 2011, 59, 30-46. (In Chinese)

56. Dwyer, A.; Zoppou, C.; Mielsen, O.; Day, S.; Roberts, S. Quantifying Social Vulnerability: A Methodology for Identifying Those at Risk to natural Hazards; Geoscience Australia Record; Australia Government: Canberra, Australia, 2004.

57. Chen, L.C. A Study on the Vulnerability and Resilience Assessment of Spatial Planning and Management in Community-Level Area; National Science Council: Taipei, Taiwan, 2009. (In Chinese)

58. Fekete, A.; Damm, M.; Birkmann, J. Scales as a challenge for vulnerability assessment. Nat. Hazards 2009, 55, 729-747. [CrossRef]

59. Granger, K.; Jones, T.; Leiba, M.; Scott, G. Community Risk in Cairns: A Multi-Hazard Risk Assessment; Commonwealth of Australia: Canberra, Australia, 1999.

60. Schmidt-Thomé, P. The Spatial Effects and Management of Natural and Technological Hazards in Europe. Available online: https://www.espon.eu/export/sites/default/Documents/Projects/ESPON2006Projects / ThematicProjects/NaturalHazards/fr-1.3.1_revised-full.pdf (accessed on 6 December 2016).

61. Hsiao, H.C. Establishing a Flood Hazard Vulnerability Assessment Model-A Case of Shijhih City. Master's Thesis, Chinese Cultural University, Taipei, Taiwan, 2008. (In Chinese)

62. Yap, K.H. Assessment of Social Vulnerability of Environmental Disasters in Taiwan; Taiwanese Sociological Association: Taipei, Taiwan, 2010. (In Chinese)

63. Deduce, C. Indicators Guideline: To Adopt and Indicator-Based Approach to Evaluate Coastal Sustainable Development; Department of the Environment and Housing, Government of Catalonia: Barcelona, Spain, 2007.

64. Wu, J.Y.; Huang, Y.S. The Establishment of Vulnerability Evaluation Indexes: The Case Study on Shuili Township, Nantou. City Plan. 2011, 38, 195-218. (In Chinese)

65. Bolin, R.; Stanford, L. Shelter, housing and recovery: A comparison of U.S. disasters. Disasters 1991, 15, 24-34. [CrossRef] [PubMed]

66. Heijmans, A. Vulnerability: A Matter of Perception; Benfield Greig Hazard Research Centre: London, UK, 2001.

67. Wilhelmi, O.V.; Wilhite, D.A. Assessing vulnerability to agricultural drought: A Nebraska case study. Nat. Hazards 2002, 25, 37-58. [CrossRef] 
68. Fischhoff, B.; Slovic, P.; Lichtenstein, S.; Read, S.; Combs, B. How safe is safe enough? A psychometric study of attitudes toward technological risks and benefits. Policy Sci. 1978, 9, 127-152. [CrossRef]

69. Slovic, P. Perception of Risk; Earthscan: London, UK, 2000.

70. Anderson, M.B. Vulnerability to Disaster and Sustainable Development: A General Framework for Assessing Vulnerability. In Storms; Pielke, R., Pielke, R., Eds.; Routledge: London, UK, 2000; Volume 1, pp. 41-51.

71. Schmidt-Thomé, P.; Kallio, H.; Jarva, J.; Tarvainen, T.; Greiving, S.; Fleischhauer, M.; Peltonen, L.; Kumpulainen, S.; Olfert, A.; Bärring, L.; et al. The Spatial Effects and Management of Natural and Technological Hazards in Europe; The ESPON Monitoring Committee: Luxembourg, 2005; pp. 1-197.

72. Birkmann, C.; Dumitru, R.C.; Prokosch, H.U. Evaluation of health-related Internet use in Germany. Methods Inf. Med. 2006, 45, 367-376. [PubMed]

73. Schneiderbauer, S.; Ehrlich, D. Social Levels and Hazard (in) Dependence in Determining Vulnerability. In Measuring Vulnerability to Natural Hazards: Towards Disaster Resilient Societies; Birkmann, J., Ed.; United Nations University Press: New York, NY, USA, 2006.

74. Peng, K.H.; Lin, S.M. A Study on the Assessment Criteria and Weight Distribution of Seismic Hazards in the Urbanized Areas of Taiwan. J. Archit. 2011, 53, 57-77. (In Chinese)

(C) 2016 by the authors; licensee MDPI, Basel, Switzerland. This article is an open access article distributed under the terms and conditions of the Creative Commons Attribution (CC-BY) license (http:/ / creativecommons.org/licenses/by/4.0/). 